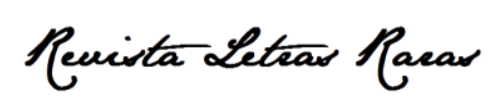

\title{
Without you: uma análise da transposição para o português do
}

\section{conto de Del James /}

\section{Without you: An analysis of the transposition into Portuguese of}

\section{Del James' short story}

\section{Rafael Francisco Pellin Grando *}

Docente de Língua Portuguesa e Inglesa para o Ensino Fundamental Series Inicias e Finais na rede privada de ensino, Mestre em Letras pela Universidade Tecnológica Federal do Paraná, Câmpus Pato Branco. Pesquisador nas áreas da Linguística Textual e Estudos da Tradução.

D https://orcid.org/0000-0003-4830-0566

\section{Mirian Ruffini *}

Docente de Magistério Superior na Universidade Tecnológica Federal do Paraná, Campus Pato Branco, Departamento e Coordenação de Letras, DALET/COLET. Docente pesquisadora do Programa de Pósgraduação em Letras da UTFPR - Campus Pato Branco (PPGL). Doutora em Estudos da Tradução, Mestre em Letras e Especialista em Língua Inglesa e Literatura de Língua Inglesa. Licenciada em Letras Português-Inglês. Atua na área de Letras, principalmente nas seguintes subáreas: Tradução Literária, Estudos de Tradução, Língua Inglesa e Literatura de Língua Inglesa, Literatura Comparada.

iD https://orcid.org/0000-0002-3222-2519

Recebido: 23 jan. 2020 . Aprovado: 26 set. 2020.

\section{Como citar este artigo:}

GRANDO, Rafael Francisco Pellin; RUFFINI, Mirian. Without you: uma análise da transposição para o português do conto de Del James. Revista Letras Raras. Campina Grande, v. 9, n. 4, p. 169-184, dez. 2020.

RESUMO:

Este artigo discorre sobre a transposição do conto Without You do autor norte-americano Del James, um autor à margem na esfera literária, sendo seus maiores trabalhos contos de terror e seu livro, A linguagem do medo. A transposição teve como língua de partida o Inglês e a língua alvo a língua portuguesa, em especial, o português brasileiro. A obra analisada foi proveniente de uma tradução realizada por um grupo de fãs da banda norte-americana Guns N' Roses chamado GNR Devotion Fan Club e para tal, não tiveram um mecenas e nem realizaram a tradução com fins lucrativos. As análises foram realizadas a partir das teorias de autores dos estudos da tradução, como Itamar Even-Zohar (2013), Andre Lefevere (2007) e Susan Bassnet (2003). Este artigo teve como objetivo verificar se a tradução preserva as características de estilo de Del James, se ela pode ser considerada uma tradução adequada e quais outras características é possível perceber nessa adaptação.

PALAVRAS-CHAVE: estudos da tradução; transposição; Guns N' Roses; Del James;

$\triangle$ rafaelfrancisco@outlook.com.br

$\triangle$ m.ruffini95@gmail.com 


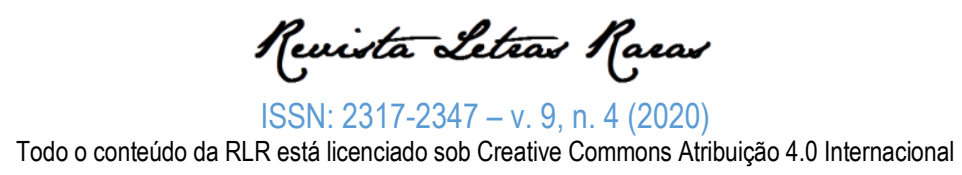

ABSTRACT:

This essay discusses the transposition of the short story Without You by the American author Del James, a writer on the sidelines in the literary sphere, his greatest works being tales of terror and his book. The language of fear. The transposition had English as its source language and the target language was Portuguese, especially Brazilian Portuguese. The analyzed work came from a translation carried out by a group of fans of the American band Guns $N$ 'Roses called GNR Devotion Fan Club and for that, they did not have a sponsor or carry out their translation for profit. The analyzes were performed based on the theories of authors of translation studies such as Itamar Even-Zohar (2013), Andre Lefevere (2007) and Susan Bassnet (2003). This article aimed to verify whether the translation preserves Del James' style characteristics, whether it can be considered an adequate translation and what other characteristics can be perceived in that adaptation.

KEYWORDS: translation studies; transposition; Guns N 'Roses; Del James;

\section{Introdução}

Em 1992, em pleno auge de sua carreira, a banda norte-americana Guns N'Roses lançou um dos mais icônicos videoclipes da história do Hard Rock, intitulado November Rain. 0 clipe retrata uma trágica história de amor de um casal exibindo momentos do seu casamento, da festa e, logo em seguida, do velório da noiva, que inesperadamente morre sem explicação.

O videoclipe teve inspiração em um dos contos do escritor e jornalista americano Del James, intitulado Without You, o qual foi publicado em seu primeiro livro, The Language of Fear, de 1995, porém, escrito antes de 1987. No Brasil, o livro de Del James nunca foi publicado e seu único conto traduzido, Without You, aparece em alguns sites que compartilham informações de bandas de Rock por toda a internet. A tradução mais popular está disponível no site Scridb e foi realizada em 2004 por um grupo de fãs da banda americana Guns N'Roses, grupo esse chamado GNR Devotion Fan Club, devido à ligação entre o clipe da música e o conto de Del James.

Com base e motivação nessas questões, este artigo propõe analisar a transposição do conto originário de Del James, em sua tradução para o português-brasileiro, realizada pelo grupo GNR Devotion Fan Club, em 2004. Esta análise apresenta aspectos relevantes sobre o autor, seu estilo, suas obras realizadas, bem como realiza cotejo da tradução mencionada com o texto fonte. Para essa finalidade, utilizam-se textos teórico-críticos de autores sobre os estudos da tradução, como Even-Zohar (2013) que aborda a Teoria dos Polissistemas Culturais, Susan Bassnett (2003), com suas contribuições sobre equivalência e a defesa de uma tradução orgânica e André Lefevere (2007), com destaque de sua visão sobre o mecenato no campo da tradução literária.

Como estrutura, primeiramente discute-se sobre o autor e o contexto de origem do conto; em seguida, apresentam-se autores do campo dos estudos da tradução para fundamentar as análises, aqui empreendidas, com suas teorias. Na seção seguinte, inclui-se a análise da 


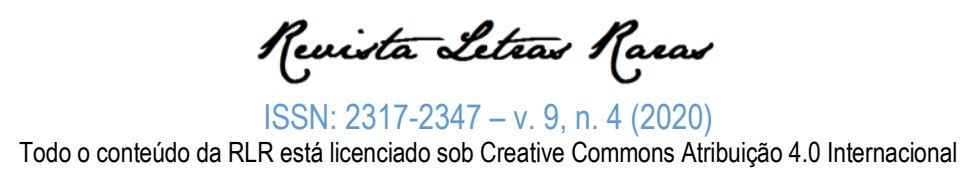

transposição do conto de Del James pelo grupo GNR Devotion Fan Club, a qual é realizada por meio de comparação entre trechos da obra de origem com a tradução para a língua alvo. As considerações geradas a partir da análise pretendem verificar se a adaptação preserva o estilo de escrita de Del James, bem como outros aspectos, concernentes à manutenção dos efeitos de sentido e às escolhas lexicais e sintáticas, presentes no conto.

\section{Del James, o autor, e o contexto do conto Without You}

Adalberto James Miranda, conhecido pelo nome artístico de Del James, nasceu em 1964 em Nova York, nos Estados Unidos da América. Além de escritor, Del James também é jornalista, chegando a se tornar Editor Sênior para a revista RIP, de Heavy Metal. $O$ autor também trabalhou como músico, escrevendo letras ou sendo coautor de alguns grupos do cenário do Rock.

Segundo o site axlrosefaclube.com, Del James é conhecido por ser um grande amigo de Axl Rose, vocalista e líder da banda americana de Hard Rock, o Guns N'Roses. James inspirouse no relacionamento conturbado do astro do rock com a ex-modelo, Erin Everly, para escrever seu mais famoso conto, Without You, em 1987, e que foi lançado apenas em 1995, no livro intitulado The Language of Fear, o qual conta com outros 14 contos.

Sobre o estilo de Del James, relatado na introdução de The Language of Fear, por Axl Rose (1995, p.8), os contos de James sugerem doses de violência extrema, perversidades, inseguranças, vícios e infidelidade, bem como "um senso de destruição que pode dominar qualquer um que não consegue ter domínio das coisas". Rose também relata que, muitas vezes, Del James the telefonou após escrever um texto, sempre dizendo que iria para o inferno, lendo-o para o cantor ou enviando-Ihe um fax em seguida. Outra definição feita por Rose (1995, p.8), sobre as obras de Del James, é que ele "pinta um quadro vivo das pessoas" devido a todos os elementos que James aborda em suas obras.

Apesar de não acreditarmos na sacralização do texto-fonte, quando este é contrastado à sua tradução ou adaptação, e procurarmos adotar análise voltada ao texto de chegada, conforme preconiza Gideon Toury, em seu livro teórico Descriptive Translation Studies and Beyond (2012), torna-se relevante tratarmos das temáticas adotadas por James, bem como as motivações para seu processo de escrita, para tecermos, em seu local apropriado, as devidas considerações a respeito do texto de chegada.

Visto que o conto de Del James se inspira em um relacionamento de seu amigo, Axl Rose, é crucial entender o contexto histórico da época em que ele foi escrito. No final da década de 1980 


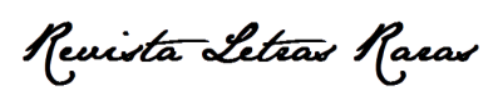

ISSN: 2317-2347 - v. 9, n. 4 (2020)

Todo o conteúdo da RLR está licenciado sob Creative Commons Atribuição 4.0 Internacional

e início da década de 1990, segundo sites relacionados especializados em músicas desse gênero, como tenhomaisdiscosqueamigos.com e wishplash.net, o cenário musical viveu uma ótima época para os amantes do Rock. A banda Queen, liderada pelo icônico vocalista Freddie Mercury, terminava a turnê de $A$ Kind of Magic. Além disso, o grupo Guns N' Roses lançava o que iria se tornar o álbum de estreia mais vendido de todos os tempos, Appetite for Destruction, e o disco ...And Justice for All, da banda Metallica chegava ao $6^{\circ}$ lugar na Billboard. ${ }^{1}$

De acordo com a teoria dos polissistemas cunhada por Even-Zohar (2013), os subsistemas da cultura, sociedade e literatura, dentre outros, em determinado contexto, interagem, influenciam e são influenciados pelos intercâmbios entre as pessoas. Esses fenômenos ocorrem dentro de um sistema ou entre sistemas, por exemplo, no âmbito social, no mundo literário, etc. Para o pesquisador da literatura e da tradução literária, esses dados podem ser subsídios valorosos na compreensão sobre a migração de uma obra literária para outro sistema estrangeiro, sobre a constituição de um texto ficcional baseado em ocorrências da vida real e do contexto social de um determinado autor, etc. Dessa forma, a exploração do entorno de James, seu tempo, seus amigos e motivações nos são caros no estabelecimento de um texto originário, que vem mais tarde a ser adaptado para uma língua e cultura brasileira, como no caso de Without You.

Com vários exemplos de relacionamentos destrutivos no sucesso mundo musical e com o seu melhor amigo passando por situações similares, Del James, por meio de seu estilo direto e sombrio, retrata em Without You (1995) um relacionamento entre Mayne, uma estrela do rock dominada por vícios e perversões e Elizabeth, uma jovem inocente. O relacionamento do casal e os momentos felizes são enaltecidos, porém, durante o conto inteiro, a perda e o sentimento de culpa predominam na narrativa. Especulamos aqui a possível transferência desses campos semânticos na tradução do conto, porquanto que os sentimentos negativos e os conflitos amorosos aparentam compor a história.

Especificamente sobre o conto Without You, seu enredo gira em torno do personagem Mayne, um músico famoso de uma banda de Rock que alcançou sucesso, mas acabou perdendo o amor de sua vida devido a um momento de infidelidade. A dor da separação fez com que Mayne

\footnotetext{
${ }^{1}$ Junto ao sucesso das bandas de rock, escândalos de uso de drogas e relações conturbadas marcavam a época. 0 site Crasso News, em um artigo chamado Love Kills: Histórias de amor trágicas do mundo da música, discorre sobre os casos mais famosos, como o suicídio de Kurt Cobain, da banda Nirvana, em 1994, a tragédia amorosa de Sid Vicious, baixista do Sex Pistols e Nancy Spungen, devido ao consumo de drogas. E, obviamente, sendo uma das inspirações de Del James, Axl Rose também protagonizou um relacionamento complexo com Erin Evelyn, com ameaça de suicídio e divórcio.
} 


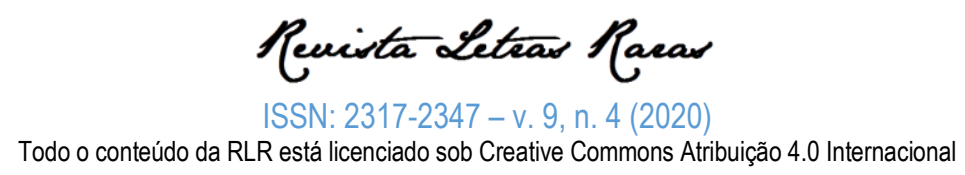

escrevesse o que viria a se tornar o maior sucesso de sua carreira, a música Without You. A música, por meio dos olhos do personagem, seria seu lado da história e não uma desculpa. Metade dos direitos de Without You foram oferecidos para Elizabeth por Mayne, mas ela os declinou.

Quando a turnê que divulgava o sucesso da música de Mayne chegou até Los Angeles, 0 músico decidiu procurar por Elizabeth, pois estava na cidade onde ela morava. Mayne seguiu até seu apartamento e enviou-lhe uma mensagem antes de subir, dizendo que a visitaria, de qualquer forma, porque ainda se importava com ela. Ao sair do elevador no andar do apartamento de Elizabeth, Mayne escuta uma música ao fundo que, à medida que se aproximava, soava cada vez mais alta até que, então, seu mundo desabou ao ouvir um barulho seco de um disparo de arma de fogo. Mayne correu até o apartamento e encontrou Elizabeth ensanguentada em seu sofá, com rascunhos de uma carta ao seu lado.

Depois de um tempo, em um episódio de depressão profunda, somada ao efeito de drogas e álcool, Mayne, em seu apartamento, observava o álbum de fotos de Elizabeth e, nesse momento, o personagem começa a destruir toda a mobília da casa devido ao sofrimento. Del James retrata perfeitamente seu dom artístico nessa cena e, somada às palavras de seu amigo, Axl Rose, na introdução, um pedaço da alma perturbada do personagem, ao ver, na última página do álbum de fotografias, 0 atestado de óbito de sua amada. Mayne se entrega aos prazeres superficiais que 0 libertavam da dor provisória da perda de Elizabeth, terminando por atear fogo ao seu apartamento, enquanto ele tocava as notas de seu maior sucesso ao piano.

Ao concluirmos esta seção a respeito da constituição da obra fonte, seu contexto de produção e as possíveis motivações e influências intersistemáticas em sua concepção, pelo autor Del James, explanamos, a seguir, sobre as teorias tradutórias que embasam as análises e discussões da adaptação do conto.

\section{Os estudos da tradução}

Como o intuito deste artigo é analisar a transposição do conto Without You do inglês americano para o português brasileiro, se faz pertinente embasá-lo nos textos dos teóricos dos estudos da tradução. Esses consistem em uma área que abrange estudar elementos de traduções, sistematizando e teorizando o processo do tradutor em relação à obra no contexto de partida e de chegada, por meio da análise dessas transferências culturais, linguísticas e semânticas.

Para a transposição do conto de Del James, é oportuno utilizar-se da Teoria dos Polissistemas, uma vez que os textos fonte e alvo trabalham com dois sistemas diferentes. 0 conto 


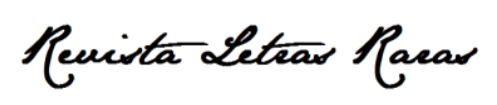

Todo o conteúdo da RLR está licenciado sob Creative Commons Atribuição 4.0 Internacional

se origina em um sistema inicial americano, que possui o inglês como língua de partida, e chega até o sistema brasileiro, tendo como língua alvo o português. Segundo o próprio Even-Zohar (2013) é mais do que uma convenção terminológica, pois seu propósito é explicitar uma concepção do sistema como algo dinâmico e heterogêneo, logo que possui vários sistemas diferentes e que eles se relacionem uns com os outros. Verifica-se, no caso do conto, sua migração entre sistemas culturais, linguísticos e literários e, assim, o movimento entre fonte de inspiração literária, musical e, mais tarde, tradutória, indica a pertinência de nossas análises.

Em específico, os sistemas podem ser configurados como redes dinâmicas, possuindo hierarquia em estratos formados pelas relações intra e intersistêmicas de seus elementos. Apesar de os sistemas ocuparem espaços concorrentes, funcionam como um todo estruturado com membros interdependentes e a sua concorrência gera uma tensão contínua entre o centro e a periferia do polissistema. (CARDOSO, 2015).

Similar ao argumento de Even-Zohar sobre a teoria dos polissistemas, a teórica da escola da manipulação, ou dos estudos culturais da tradução, Susan Bassnett (2003), comenta que o processo tradutório não é simplesmente linguístico ao transferir-se o sentido contido em um conjunto de signos linguísticos pelo intermédio de recurso competente ao dicionário e à gramática. Bassnett (2004) ainda diz que o processo tradutório envolve um vasto conjunto de critérios extralinguísticos e nesse ponto a teoria de Even-Zohar (2013) se encontra com as palavras da autora, pois ambos corroboram que cada língua pertence a um sistema diferente e cada qual possui suas particularidades. Assim, adaptar uma obra literalmente pode não exprimir o seu real sentido.

José Lambert, outro autor que defende o processo tradutório como mais que uma adaptação linguística, constata o seguinte:

As compatibilidades ou incompatibilidades nunca são absolutas; são históricas e, portanto, relativas, mesmo no plano linguístico. A questão da possibilidade das traduções torna-se, desta forma, uma questão histórica e relativa, que os tradutores resolvem com seus próprios meios e concepções, ou com meios e concepções aceitos por seus meios. (LAMBERT, 2001, p. 197)

Em outras palavras, a tradução ou adaptação de uma obra da língua de partida para outra língua de chegada não deve se basear especificamente na questão gramatical da língua alvo, relacionando as palavras utilizadas equivalentes àquelas da língua de origem. Faz-se necessário, portanto, analisar as questões históricas da língua bem como outras particularidades como, por 


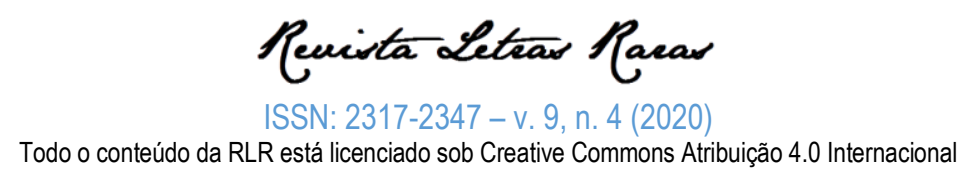

exemplo, expressões idiomáticas, que ao serem traduzidas de forma literal, perdem seus sentidos originais.

Após ter noções sobre os sistemas que estão presentes no processo tradutório, parte-se então para outro ponto muito pertinente a ser explorado sobre os estudos da tradução, o mecenato na transposição de uma obra literária. O mecenato pode ser visto com um conjunto de agentes que fomenta arte e cultura. Da mesma forma que há vários sistemas na transposição de obras, como visto nas teorias de Even-Zohar (2013), no mecenato também há um complexo sistema de sistemas, composto de vários subsistemas, os quais interagem entre si constantemente.

Andre Lefevere (2007) discute sobre o mecenato, levantando algumas de suas características e relacionando-o com a literatura. 0 autor argumenta que a literatura é um dos sistemas que está presente no complexo "sistema de sistemas" conhecido como cultura. A cultura e a sociedade estão diretamente relacionadas ao ambiente do sistema literário. Essas noções reforçam a ideia de os sistemas estarem ligados entre si e fortalecem a questão de a literatura ser também uma grande forma de manifestação cultural de grupos, etnias e povos.

O mecenato possui o interesse na ideologia da literatura, bem como em sua poética e status, podendo ser exercido por pessoas ou por grupos. Devido a isso, o mecenato regula vários fatores que implicam as distribuições de obras e traduções. Lefevere (2007) comenta que existem vários agentes ou atores para essa regulação e controle no sistema literário, que são exercidos pelos mecenas, como os profissionais, resenhistas, professores e tradutores, por exemplo, que podem aceitar ou rejeitar obras consoantes ou divergentes ao conceito de poética dominante.

Para o mecenato, ainda segundo Lefevere (2007), três elementos são cruciais para 0 funcionamento do sistema. O primeiro deles se baseia na ideologia ou conteúdo das obras. Uma obra estar alinhada ao pensamento de um mecenas ou de um grupo é talvez o principal fator para a obtenção de aval e seu consequente financiamento. O segundo elemento é a questão econômica, uma vez que ela garante aos escritores e reescritores um modo de sustento, e quiçá a obtenção de lucro. Por fim, o terceiro elemento se situa no estilo de vida. O mecenato preocupase, predominantemente, com a ideologia em relação à literatura, visto que 0 status que essas obras literárias adquirem se apresenta mais pertinente para o aspecto mercadológico do mecenato do que apenas a beleza e a arte subjacentes.

Assim como muitas obras situam-se à margem da literatura, o mecenato também não é um sistema uniforme, podendo ser dividido nos modos indiferenciado e diferenciado. Lefereve (2007) aponta que o mecenato indiferenciado é aquele que possui os três elementos (ideologia, 


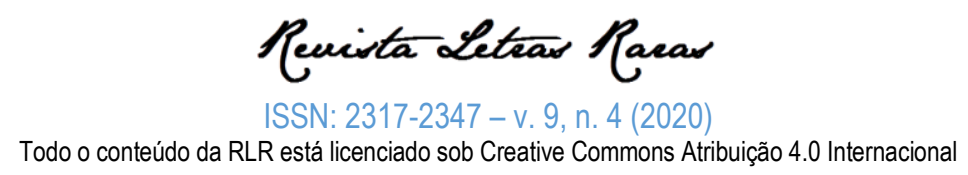

economia e status) providos por um agente, enquanto o mecenato diferenciado se dá quando 0 sucesso econômico é relativamente independente dos fatores ideológicos e não traz o status, 0 que torna o tradutor, ou o processo tradutório, mais independente.

Após realizada a discussão teórica, parte-se, na sessão seguinte, para as análises da transposição do conto de Del James para a língua portuguesa

\section{Análise}

Com base nos estudiosos que dialogam sobre os estudos da tradução, o primeiro ponto de análise neste artigo sobre a transposição do conto Without You, de Del James, para o português brasileiro, é a configuração das formas de tradução dessa obra. Como mencionado anteriormente, o mecenato exerce um papel bastante dominante na literatura, pois, devido a vários fatores, regula como uma obra pode ser adaptada para outra língua ou até mesmo que ela seja descartada, por não seguir a mesma linha ideológica com a qual o mecenas se identifica.

Um ponto necessário para fomentar essa análise é que a obra de origem, Without You, provém de um autor situado à margem da literatura americana, com pouco destaque e relevância. O gênero que James aborda, o horror, possui nomes icônicos na literatura, como Stephen King, na atualidade, Edgar Alan Poe, como escritor clássico e, mais recentemente, Lovecraft, que embora seja um escritor do final do século XIX e início do século XX, se torna popular muitos anos após sua morte. Dessa forma, aplicando-se a noção de periferia e centro no que se refere aos textos literários, explanada pelos teóricos Even-Zohar (2013), Gideon Toury (2012), dentre outros, percebe-se que a obra de James ocupa uma posição periférica na literatura, enquanto os outros autores mencionados fariam parte do cânone literário do gênero de terror. Exploramos, a seguir alguns possíveis motivos para essa avaliação da literatura de James.

Apesar de existir público para o estilo e gênero que James utiliza em suas obras, o autor nunca obteve tanto destaque no ramo literário, o que pode ser justificado por alguns fatos. Del James não publicou muitas obras ao longo de sua carreira, sendo o seu único livro conhecido, até então, The Language of Fear. Há também outra obra em que James faz parceria com outros escritores, intitulada Halloween Carnival pt 2, a qual é uma compilação de histórias da mesma temática, editada por Brian James Freeman. Outro motivo para justificar o pouco destaque de James foi a mescla de sua vida literária com a carreira musical, o que levou 0 autor a ter vários focos durante sua vida e contribuiu para que seu nome na esfera literária não fosse difundido. 


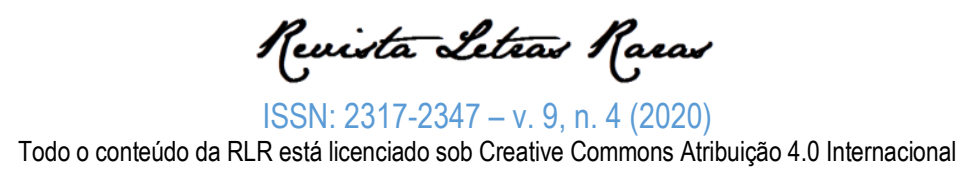

Expostos esses fatos sobre Del James, conhecemos que a tradução do inglês para 0 português de seu conto, Without You, aconteceu por meio de um grupo de fãs brasileiros da banda Guns N'Roses que, conhecendo a relação entre um dos maiores sucessos do grupo - a música November Rain -, com o conto escrito por James, resolveram adaptar o texto originário para 0 português brasileiro. Essa adaptação não recebeu influência direta de um mecenas, portanto, tratou-se de um mecenato indiferenciado, pois a tradução do conto nunca objetivou fins econômicos e sim a divulgação do conto, provavelmente para os fãs mais fieis da banda. Esses não consomem apenas as músicas e videoclipes, mas também as influências e todo o universo do grupo musical, como estilo de roupas que seus ídolos utilizam e até mesmo ideologias que eles seguem.

Tratando-se da linguagem, a escrita de Del James utiliza-se de várias metáforas para retratar o conflito de seus personagens. Um exemplo disso pode ser visto no seguinte trecho do texto-fonte, em comparação ao texto-alvo, no quadro abaixo:

Quadro 1: comparação entre conto e tradução

\begin{tabular}{|l|l|}
\hline \multicolumn{1}{|c|}{ TEXTO-FONTE } & \multicolumn{1}{|c|}{ TEXTO-ALVO (TRADUÇÃO) } \\
\hline $\begin{array}{l}\text { Her eyes sparkled, reminding him of the ocean, } \\
\text { vast with beauty and mystery. A slight breeze } \\
\text { danced through her lion's mane. A full-length } \\
\text { see-through dress covered her shapely body } \\
\text { and a light glaze of sweat made her glisten. } \\
\text { (JAMES, 1995, p. 124). }\end{array}$ & $\begin{array}{l}\text { Os olhos dela faiscavam, lembrando-lhe um } \\
\text { oceano, vasto, com toda a sua beleza e miséria. } \\
\text { Uma fraca neblina dançava através de seu corpo. } \\
\text { que cobria a figura do corpo dela e uma luz } \\
\text { envidraçada de suor a fazia brilhar. (GNR } \\
\text { DEVOTION FAN CLUB, 2004, p. 03) }\end{array}$ \\
& \\
\hline
\end{tabular}

Fonte: Quadro elaborado pelos autores

A primeira sentença da adaptação respeita bastante a questão das escolhas de palavras do autor original, bem como sua pontuação. Porém, a escolha dos tradutores responsáveis para a palavra "mystery" não foi "mistério", mas sim "miséria". Essa escolha reflete diretamente na construção da personagem, uma vez que descrever Elizabeth como misteriosa provavelmente não provocaria o mesmo impacto como o termo miserável, no sentido de triste ou infeliz. Tomando-se o conto como um todo orgânico e as construções que James fez de sua personagem, a equipe de tradução possivelmente considerou que a personagem se enquadrava mais como infeliz do que misteriosa e, portanto, a escolha parece respeitar o que é retratado por James e permite aos leitores de língua portuguesa captar a essência da personagem Elizabeth. 


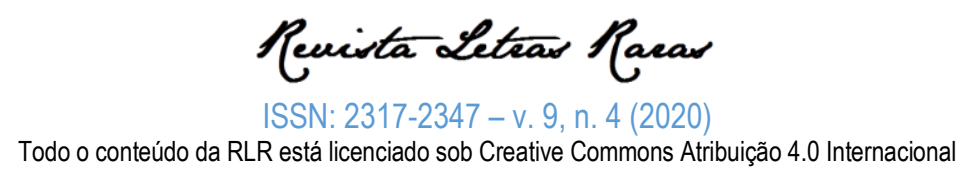

Susan Bassnett (2003) defende uma abordagem em que a organicidade da tradução seja priorizada. A pesquisadora trata a respeito da tradução poética nesses termos, defendendo que forma, aspectos semânticos, rimas e outros elementos da poesia sejam levados em conta em conjunto, e não separadamente. Ao aplicarmos o postulado da teórica à tradução do conto, do gênero prosa curta ficcional, percebemos sua pertinência, visto que, idealmente, todos os elementos da narrativa devam ser almejados, na tradução, como, por exemplo, o enredo, a constituição das personagens, o tipo de narração, entre outros. No caso da tradução de Without You, o grupo aparentemente constrói a adjetivação para a personagem baseando-se no tom trágico e melancólico do conto, e não apenas nos trechos de sua aparição, dentro do conto.

Na segunda parte do trecho, há uma alteração mais significante, pois enquanto James descreve fisicamente Elizabeth, referindo-se aos seus cabelos como uma juba de leão (lion's mane), a adaptação tira a metáfora comparativa e simplesmente a substitui pela palavra "corpo". Como um todo, o trecho não sofre prejuízo de sentido, porém, demonstra que há perda de detalhes que contribuem para a criação da imagem mental da personagem para o leitor. Essa troca levanta a questão da equivalência ao traduzir uma obra. Rodrigues (2000) diz o seguinte sobre a equivalência:

A noção de equivalência como proposta nos textos em que é central pressupõe que os intercâmbios lingüísticos possam se realizar com perfeito equilíbrio, em uma relação idealizada entre povos e culturas, em que duas línguas estão em posição simétrica. Pensar sobre a questão da multiplicidade de línguas e a da violência cultural, significa desmascarar essa noção de equilíbrio, pois as escolhas do tradutor sempre apontam para a construção de valores - que nunca estão em perfeita simetria (RODRIGUES, 2000, p. 92).

Em outras palavras, as línguas possuem estruturas próprias, uma perfeita simetria é algo dificilmente alcançado e quando um tradutor troca palavras para manter o sentido em uma tradução, ele está fazendo sua opção tradutória mais apropriada para aquele momento. Bassnett (2003) ressalta há quatro tipos de equivalência: a linguística, que se dá palavra por palavra, a pragmática, por número de elementos, estilística, que remete a peculiaridades do escritor fonte, e a textual, quando há equivalência de forma. No trecho recortado da adaptação anteriormente, como exemplo de Without You, bem como no conto completo, não aparenta haver uma preocupação com nenhuma das equivalências comentadas por Bassnett e sim em uma equivalência de sentidos que o conto original propõe despertar. Outro exemplo de que não há, aparentemente, equivalência em algum dos quatro pontos apresentados por Bassnett é que no texto originário, o trecho recortado no exemplo da obra original está situado no meio de um 


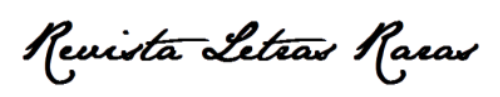

ISSN: 2317-2347 - v. 9, n. 4 (2020)

Todo o conteúdo da RLR está licenciado sob Creative Commons Atribuição 4.0 Internacional

parágrafo, enquanto na adaptação realizada pelo GNR Devotion Fan Club essa parte está no início de um novo parágrafo, ou seja, não há equivalência de forma.

Outro ponto pertinente sobre a equivalência é abordado por Oliveira (2007), autora que constata:

Inegavelmente, a disciplina dos Estudos da Tradução trouxe inovações ao pensamento sobre tradução e sobre equivalência. Propiciou aos que se preocupam com a tradução campos de pesquisa que ultrapassavam a rigidez desejada pela lingüística tradicional e, ao adotar posições ligadas à recepção do texto e à atuação do tradutor como agente cultural, mostrou que a equivalência só poderia se dar de forma contextualizada e negociada, o que, de alguma forma, põe em destaque o fato de a tradução não ser simples repetição das palavras do autor em uma outra língua. (OLIVEIRA, 2007, p. 105).

A partir do que diz Oliveira (2007), na tradução do conto Without You, o eixo paradigmático escolhido por James, ao escrever sua obra, não é o mesmo do qual o grupo GNR Devotion Fan Club optou para traduzir o conto para o português. Não sendo essa uma repetição de palavras, como a autora argumenta, novamente mostra que o grupo optou por preservar o sentido e não a escolha de palavras.

Partindo para outro exemplo, o conto de Del James possui diálogos e esses respeitam o padrão americano, com o uso de aspas para informar o leitor que aquilo não é narração e sim a fala de um personagem. Isso pode ser verificado no exemplo do quadro abaixo da obra de James, e o mesmo trecho de diálogo, dessa vez, na adaptação para o português:

Quadro 2: Comparação entre conto e tradução 


\section{Penista Letras Paras}

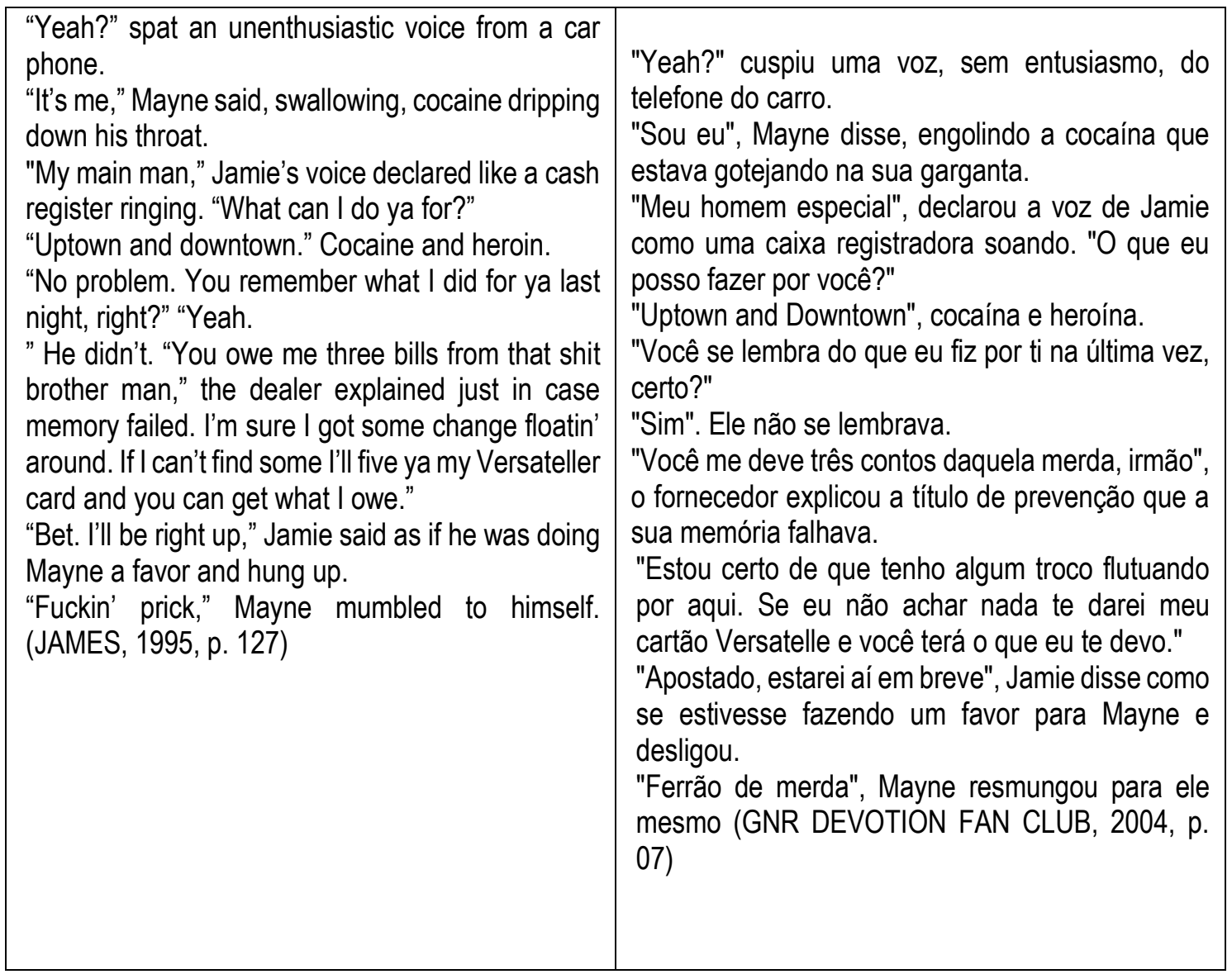

Fonte: Quadro elaborado pelos autores

Curiosamente, a equipe de tradução do conto Without You optou, ao adaptar a obra para a língua portuguesa, por manter as indicações de diálogos do original, utilizando as aspas. Geralmente, o padrão português brasileiro, utilizado nos livros narrativos, possui o diálogo iniciado por um recuo ou também conhecido por "parágrafo" e seguido pelo popular "travessão". Similar ao hífen, porém, de maior tamanho, esse se apresenta seguido da fala do personagem, outro travessão e então a sequência narrativa.

Um exemplo de padrão de diálogo de obras em língua portuguesa, o qual utiliza travessão para indicar discurso direto, pode ser conferido da seguinte maneira:

- Você demorou! - Disse Lisa para sua esposa, Victoria chegava perto das nove horas do departamento de polícia.

- Desculpe por não ter avisado. Hoje o dia estava cheio, precisei ficar até mais tarde e terminar o relatório de um desaparecimento - Respondeu Vick tirando seus calçados. (Exemplo dos autores)

Além da peculiar decisão de manter as aspas para indicar o diálogo ao invés do parágrafo e travessão, como é normalmente utilizado, há outros dois detalhes nesse mesmo recorte da 


\section{Reuista Letear Pacar}

ISSN: 2317-2347 - V. 9, n. 4 (2020)

Todo o conteúdo da RLR está licenciado sob Creative Commons Atribuição 4.0 Internacional

adaptação que merecem ser citados. O primeiro deles é que o grupo não traduziu as expressões "Uptown" e "Downtown" as quais se referiam respectivamente em português para "parte afastada da cidade" e "Centro", sendo apelidos para as drogas que Mayne pediu ao traficante. A escolha de não traduzir essas palavras pode se dar por dois motivos: Não haver equivalente como palavra única para "uptown" no português, ou então, seguir uma linha de tradução mais estrangeirizante, nos termos de Lawrence Venuti, veiculados em sua obra Os escândalos da tradução (2002), aquela mais ligada ao contexto de partida e portadora de seus resíduos culturais, ao invés de domesticante, ou seja, mais centrada no contexto de chegada e de leitura mais fluente para o leitor da tradução, o que pode ir ao encontro da escolha de utilizar as aspas para o diálogo.

O segundo detalhe é que as palavras chulas, ou turpilóquios, utilizados por James, não foram censurados pelo grupo GNR Devotion Fan Club. Essa ausência de censura pode ter acontecido devido ao fato de o grupo não estar ligado a um mecenas, os quais podem coibir palavras obscenas para atender um público maior, ou por qualquer outra razão ideológica. Alguns trechos com estas palavras foram traduzidos literalmente e, por vezes, não apresentam o real sentido do contexto utilizado para a expressão, sendo uma delas um palavrão ligado à palavra "prick", sendo ela adaptada para "ferrão". O uso desta adaptação, mesmo dentro do contexto, não deixa claro o que o personagem está dizendo, pois não há nada na língua alvo relacionado à expressão da língua de partida, sendo ela uma expressão de alegria ou comemoração.

Apesar da opção mais suavizada da tradução da expressão "prick", a não censura adotada pelo grupo durante a adaptação pode ter sido intencional ou apenas de forma coincidente para preservar o estilo de Del James, o qual inclui, em seus contos, uma quantidade de palavras licenciosas bastante presentes. Uma justificativa seria que celebridades do Rock, muitas vezes, são surpreendidas verbalizando tais palavras e isso pode ter influenciado James no seu processo de escrita de Without You e, por sua vez, preservado pelos tradutores da adaptação em português.

Outros dois pontos bem pertinentes a serem comentados sobre a tradução para 0 português brasileiro foi que o grupo GNR Devotion Club modificou levemente o nome de um dos personagens do conto. Enquanto na obra de origem Del James utiliza "Elizabeth", os tradutores optaram por utilizar "Elisabeth", fazendo a troca do "Z" pelo "S". Essa alteração quebra, aparentemente, padrões estrangeirizantes que até então eram adotados na adaptação e domestica o nome da personagem de forma escrita mais próxima ao modelo da língua alvo.

O segundo fato é um ponto negativo para a adaptação, tratando-se de desvios da norma padrão da língua portuguesa. Em mais de dez ocorrências, os tradutores deixaram de pontuar 


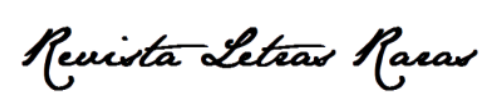

ISSN: 2317-2347 - v. 9, n. 4 (2020)

Todo o conteúdo da RLR está licenciado sob Creative Commons Atribuição 4.0 Internacional

corretamente com vírgula antes da conjunção adversativa "mas". A ausência de virgula, algumas vezes, parece ser devido à própria obra de origem, na qual em determinadas sentenças, James não utiliza a vírgula, porém, no português, antes de "mas" deve-se utilizar a pontuação para respeitar a norma padrão da língua. No inglês, por sua vez, há regras específicas que permitem ambos os casos. Para sentenças permanecerem sem a vírgula, as frases devem possuir cláusulas que não são independentes; por outro lado, quando as sentenças possuem cláusulas independentes é necessário o uso da vírgula. 0 desvio que o grupo GNR Devotion Club realizou pode ser conferido no seguinte trecho: "Certas guitarras traziam memórias mas cada guitarra tinha a habilidade de criar a mágica" (GNR DEVOTION CLUB, 2004, p. 12, grifo dos autores).

Apesar dessas ocorrências, há também raros casos em que a tradução respeitou a norma padrão da língua portuguesa, inserindo vírgulas em trechos que na obra original não possuía. Essas inserções podem ser comparadas nos seguintes trechos, no quadro abaixo:

Quadro 3: comparação entre conto e tradução:

\begin{tabular}{|l|l|}
\hline \multicolumn{1}{|c|}{ TEXTO-FONTE } & \multicolumn{1}{|c|}{ TEXTO-ALVO } \\
\hline$\ldots]$ crack, or smack to troubled celebrities, exploiting \\
$\begin{array}{l}\ldots . . .] \quad \text { crack ou heroína para celebridades } \\
\text { their vulnerabilities. Mayne searched for more clues } \\
\text { as to who else had been over partying but came up } \\
\text { blank (JAMES, 1995, p. 125). }\end{array}$ & $\begin{array}{l}\text { Mayne procurou mais vestígios de quem mais } \\
\text { esteve fazendo festa lá, mas veio um branco (GNR } \\
\text { DEVOTION CLUB, 2004, p. 5, grifo dos autores). }\end{array}$ \\
& \\
\hline
\end{tabular}

Fonte: quadro elaborado pelos autores

A quantidade de desvios que a adaptação faz sobre a questão da ausência de vírgula em sentenças perante as vezes que a vírgula foi inserida na obra de destino de forma correta visivelmente leva a crer duas hipóteses: A adaptação se baseou majoritariamente na pontuação da obra de origem, ignorando a norma padrão da língua alvo e também não houve um cuidado ou até mesmo uma profunda revisão de escrita da língua portuguesa na adaptação.

Outro caso que reforça sobre a revisão da língua alvo ter sido superficial são desvios da norma padrão do português em relação à colocação pronominal de algumas sentenças. Exemplo: "Mayne acordou coberto de suor, se encolheu calado ainda com a garganta seca (GNR DEVOTION CLUB, 2004, p. 4, grifo do autor)". Nesse trecho, o pronome "se" está situado na frente 


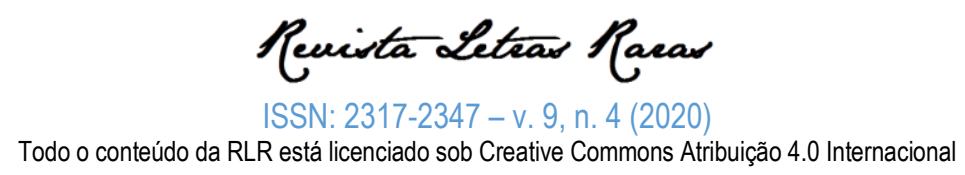

do verbo "encolher", como há uma pausa por vírgula, não há fator de atração do pronome, logo, a sentença deveria estrar escrita "encolheu-se". Uma vez realizada as análises, na seção seguinte realizam-se nossas considerações finais.

\section{Considerações finais}

Por se tratar de uma obra feita por um grupo de fãs, de forma independente, o conto Without You é adaptado de forma convincente para quem deseja conhecer mais sobre as influências da música e do clipe November Rain da banda norte americana, Guns N' Roses. 0 estilo que Del James e suas escolhas de palavras são mantidas para a transposição de Without You para a língua portuguesa, o que parece manter a característica de James retratar personagens facetados e autodestrutivos em sua obra. A não censura também contribui para dar a sensação de realismo do texto originário ou fonte, e se faz consoante às inspirações recebidas por James durante o decorrer de sua vida literária.

Contudo, nem tudo é positivo na adaptação de Without You. Como se pode perceber nos fragmentos citados, a ausência de uma revisão profunda da língua alvo ocasionou alguns problemas de pontuação e desvios de regras da norma padrão da língua portuguesa. Apesar da tentativa clara de manter-se aproximado do texto originário/fonte, ignorando vírgulas onde James não utilizava, a ausência não transforma a intenção ser mais relevante do que o respeito pelas normas.

Outra questão controversa é a escolha do padrão americano de diálogo com as aspas em um sistema literário que predomina o parágrafo e travessão para a mesma função. Essa escolha combina com a não tradução de gírias e apelidos, mantendo a adaptação com um ar mais estrangeirizante, porém, também com aspectos de domesticação ao modificar a letra do nome de um dos personagens, sendo escrito mais próximo da língua alvo. Essa mistura de elementos estrangeirizantes e domesticados não dão pistas se foram propositais ou coincidentes, sendo a hipótese mais plausível a de que o grupo tradutório simplesmente queria deixar o conto de Del James acessivel para todos, não se preocupando com detalhes técnicos de tradução.

Para concluir, como um todo, a tradução ou adaptação se apresenta bastante equivalente para com a obra original, mantém as características estilísticas do autor e entrega ao leitor uma boa leitura. Os desvios cometidos na língua alvo não tiram o brilho e a catarse que o conto de Del James oferece em seu conto original. Esses desvios, somados ao padrão americano de diálogo, 


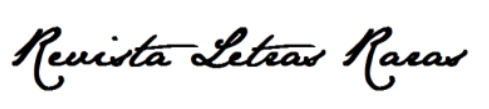

Todo o conteúdo da RLR está licenciado sob Creative Commons Atribuição 4.0 Internacional

podem até causar desconforto para leitores mais críticos, porém, de modo algum tiram todo 0 sentido e a atmosfera que a obra original possui.

\section{Referências}

BASSNETT, S. Estudos da Tradução: Fundamentos de uma disciplina. Lisboa: Fundação Cauloste Gulberkian, 2003;

BERNARDI, R. 8 artistas que se tornaram grandes com seus álbuns de estreia. Tenho mais discos que amigos, 2018. Disponível em: < http://www.tenhomaisdiscosqueamigos.com/2018/11/19/artistas-grandes-discos-estreia/> Acesso em 28 dez 2018;

BONANI, G. Love Kills: Histórias de amor trágicas do mundo da música. Crasso, 2017. Disponível em: <http://www.crasso.com.br/news/love-kills-historias-de-amor-tragicas-do-mundo-da-musica/> Acesso em 29 dez 2018;

CARDOSO, A. C. B. La Fontaine no Brasil: história, descrição e análise paratextual de suas traduções. UFSC, Florianópolis, 2015 - Tese de doutorado;

COSTA, R. Metallica: And Justice For All é um album injustiçado? Whisplash, 2007. Disponível em: < https://whiplash.net/materias/cds/061226-metallica.html> Acesso em: 28 dez 2018;

Del James. Axl Rose Fã Clube. Disponível em: <http://ax|rosefaclube.com/del-james/> Acesso em 29 dez 2018;

EVEN-ZOHAR, I. Teoria dos polissistemas. Revista Translatio 4. [Marozo, Luis Fernando, Carlos Rizzon \& Yanna Karlla Cunha trans.], 2013, pp. 2-21;

GNR DEVOTION CLUB. Sem você. in: A linguagem do medo. 2004. Disponível em: <https://pt.scribd.com/document/55947828/A-Linguagem-Do-Medo> acesso em 28 dez 2018;

JAMES, D. The Language of Fear. Nova York, 1995;

JOSÉ, C. As mulheres de Axl Rose. Axl Rose Fã Clube, 2013. Disponível em: < http://ax|rosefaclube.com/2013/04/as-mulheres-de-axl-rose/> Acesso em 28 dez 2018;

LAMBERT, J. Literatura \& tradução: textos selecionados de José Lambert / Andréia Guerini, MarieHélène Catherine Torres e Walter Costa (orgs.). - Rio de Janeiro: 7 Letras, 2011;

LEFEVERE, A. Capítulo 2: O sistema: Mecenato. In: Tradução, reescrita e manipulação da fama literária. Bauru, SP: Edusc, 2007. p. 29-49;

OLIVEIRA, A. R. de. Equivalência: Sinônimo de Divergência. Cadernos de Tradução, V1, n. 19, Florianópolis, Brasil. 97-114;

RODRIGUES, C. C. Tradução: A questão da equivalência. Alfa, São Paulo, n 44. 89-98, 2000;

ROSE, W. A. Introdução. In: JAMES, D. The Language of Fear. New York, 1995, p.8-10.

TOURY, Gideon. Descriptive Translation Studies and Beyond. 2 ed. John Benjamins B. V., 2012. 